\title{
Research on Management Information System in Copper Companies Mode of Coordination
}

\author{
Wen-jing Ren, Xue-fei Wang, Yi-dan Tang, Li-li Shan, and Zhi-lei Huo \\ Business college, Chengdu University of Technology, Chengdu ,Sichuan, China
}

\begin{abstract}
The article at the beginning analyses the significance of establishing collaborative management information system in copper companies. Then, the hierarchical structure and the mutual synergic relationship of the system are put forward. What's more, the characteristics of the system are elaborated. In the end, the author establishes a integrated collaborative management information system platform and details the modules and their functions of the subsystems. The innovation of the article is that by using the advanced theories of management of collaboration, and that system features like environmental protection, safety production, and so on are projected, which achieve the integrated and collaborative relational schema between copper companies and other organizations across the mine lots, multi-industries is set up collabrative operating capabilities and accelerate the sustainable development of the copper companies.
\end{abstract}

Key words---Coordination, Complete system, protection, Safety Production

\section{基于协同化的铜矿企业管理信息系统模式研究}

\author{
任文静 王雪飞 唐旖聑 单莉莉 霍志磊 \\ 成都理工大学商学院, 成都, 四川, 中国
}

摘 要 文章首先分析了建立铜矿企业协同化管理信息系统的意义, 其次提出该系统的层次结构以及相互间的协同关系, 并阐述了 系统的特点, 最后作者构建了完整的铜矿企业协同化管理信息系统平台, 详细描述各子系统功能模块及其功能。文章的创新之处是运 用协同化先进管理思想, 以环保、安全生产等特色的系统设计, 实现了铜矿企业整体集成能力, 铜矿企业与跨矿区、跨行业的其它组 织之间协同运作能力，促进铜矿企业的可持续发展。

关键词 协同，完整体系，环保，安全生产

1. 引言

建立协同化铜矿企业管理信息系统有以下的意义:

首先是目前中国铜矿企业管理的迫切需要。

铜是重要的有色金属原材料之一。目前铜矿企业面临 很多问题: 中国铜矿企业需要的冶炼原料对外依存度已达 $70 \%[1]$, 原料供应非常不足, 铜矿石品位逐年降低, 而铜 矿企业升级设备费、采选技术创新费、税费、环境治理费 逐年提高, 导致企业运营成本提高。要求引入现代化的管 理思想和方法来有效提高工作效率、降低成本。

其次是目前铜矿企业信息化建设的迫切需要。

铜矿企业不具备完整管理信息系统体系结构。

有些铜矿企业管理信息系统只注重重要部门（“生产”、
“财务”部门）的信息化建设。例如对“生产数据实时采集远 程监控管理系统”、“设备管理系统”的研究较多, 忽视铜矿 企业其它部门的信息化建设，工作环节断裂、工作流程无 整体控制，无法实现铜矿企业内部各个部门间协作。

有些铜矿企业只注重企业内部 ERP 的建立, 只有企业 内部局域网, 不重视与其它单位的合作, 甚至没有对外的 官方网站, 无法实现铜矿企业与其它企业的协作, 造成铜 矿企业商品流通不畅通, 商品滞销, 供应商选择不恰当, 采购价格过高, 甚至原料采购不足。

虽然大型铜矿企业有管理信息系统，但是信息非常不 完整。例如很多销售信息子系统中“产品信息”都没有详细 公布，例如“里伍铜矿”信息系统中“里伍产业”栏目下只有

四川矿产资源研究中心资助项目 (编号 sckczy2013-yb002) 
“商品名称”和“商品编号”, 而“商品详细介绍”下的内容为 空，没有建立与供应商、购买方的有效协作关系。

最后, 铜矿企业建立基于协同化思想的管理信息系统 意义。

1999 年, Gartner Group 提出协同化的基本思想: 使得 商业利益一致的合作伙伴合作, 共享整个商业周期中信息, 提高企业自身的活力, 满足不断增长的客户的需求。目前, 协同化信息系统在中国的零售业、物流、化工、制造业、 煤炭行业等很多企业已经广泛应用, 铜矿企业这种生产过 程较特殊, 管理水平相对落后, 其协同化系统还处于探索 期。

作者认为建立基于协同化的铜矿企业管理信息系统, 实现铜矿企业内部各部门信息化共享, 资源优化整合配置, 建立铜矿企业采、选、冶、科、工、贸跨地区、跨行业的 全球化互动协作, 可以降低成本, 工作流程、商品流通畅 通。

\section{2. 协同化铜矿企业管理信息系统的层次结构以及相 互协同关系}

作者认为完整的协同化铜矿企业管理信息系统应分为 三层结构。见图 1。

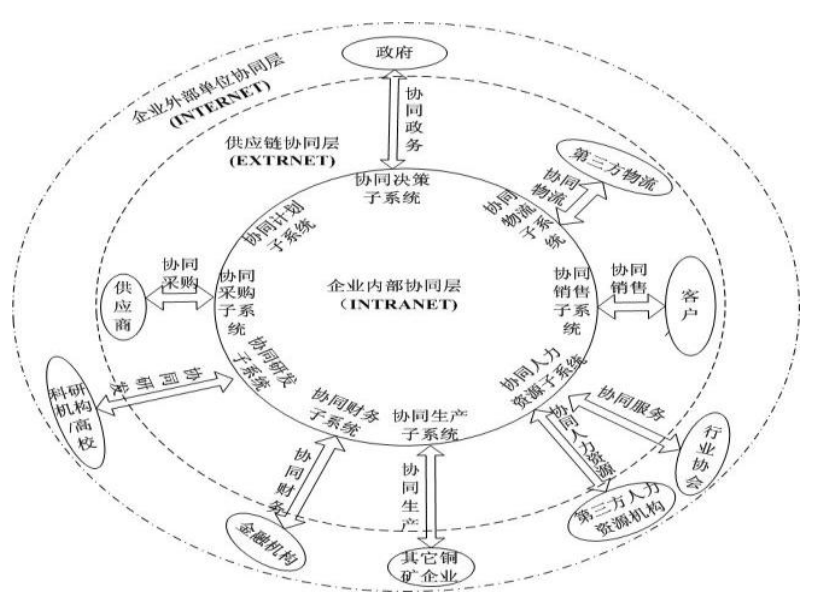

图 1 铜矿企业协同电子商务层次图

第一层是基于铜矿企业内部协同化，包括：决策协同、 计划协同、生产协同、财务协同、采购协同、销售协同、 物流协同、人力资源协同等，使得实现铜矿企业各部门间 的分工与协作, 实时控制, 精艺生产, 信息等各项资源共 享、合理配置。

第二层是基于铜矿企业供应链协同化, 铜矿企业与铜 矿石供应商、钻探、装备工具供应商、物流服务供应商; 铜矿企业与客户 (包括铜加工企业、铜工业品客户)、第三 方物流之间建立协作关系。对整个供应链的信息流、资金
流、物流、业务流进行有效规划整合, 实现 ERP、SCM、 CRM 的集成。

第三层是铜矿企业与跨矿区、跨行业的其它组织之间 的协作关系，利用互联网建立铜矿企业与政府、金融机构、 第三方服务组织 (第三方人力资源组织等)、研究所、高校 等的协作关系, 为企业建立矿区内、跨矿区的政治、经济、 法律、科研等良好发展的外部环境。

协同化铜矿企业管理信息系统不仅实现企业各职能部 门的相互协同关系，而且层次与层次间也实现了相互协同 关系。例如企业内部协同层中的的计划子系统、生产子系 统需要第二层企业供应链提供市场信息和供应商信息。企 业内部协同层中的决策子系统需要从第三层中的政府获得 政府政策信息，为内部的决策协同、计划协同做保障。

\section{3. 协同化铜矿企业管理信息系统的特点}

\section{1 先进的协同化管理思想的信息系统}

在铜矿企业中融入协同化的思想，开放的协同式的管 理信息系统, 不仅企业对内协调工作, 对外协作范围扩大, 使得传统企业充满现代化的活力。

\section{2 为安全生产服务的信息系统}

铜矿企业很多为经济利益, 忽视了安全生产的重要性, 给企业造成很恶劣的社会影响力, 给社会也带来重大损失。 在协同生产子系统中专门设计了实时保障安全生产模块, 并在成本会计模块设计的安全成本子模块, 其中专门有管 理工程项目安全成本与提取安全生产基金功能。为本系统 就安全问题提供了事前预防、事（中）后控制的保障。

\section{3 具有环保特色的信息系统}

目前中国环保问题日趋严峻, 政府对企业的环境污染 监控日趋重视, 污染严重的铜矿企业面临转型。该系统可 以促进外单位与本企业的协同研发，不再使用“湿法制铜” 这种污染严重的生产技术, 开发出环保新型生产技术, 大 力合作研制尾矿利用技术等, 并且在该系统中的环保成本 中设置了: 矿区环境保护设备费、矿区环境保护治理费、 矿区环保教育费等为做好环保预防、生产过程环保、恢复 治理工作而努力。

\section{4 重视企业内部物流的信息系统}

铜矿企业的生产部门有采矿场、选矿场、冶炼部门等, 本系统中设计生产物流模块是为保障铜矿石, 硫精矿、精 铜、危化品从采矿场到选矿场、冶炼部门安全运输, 并在 运输过程的储存中保障物料不变质、损失少。 


\section{4. 协同化铜矿企业管理信息系统的体系结构}

作者认为完整的协同化铜矿企业管理信息系统的体系 结构包括：协同决策子系统、协同计划子系统、协同生产 子系统、协同采购子系统、协同销售子系统、协同物流子 系统、协同财务子系统、协同仓储子系统、协同研发子系 统、协同人力资源子系统等。见图 2:

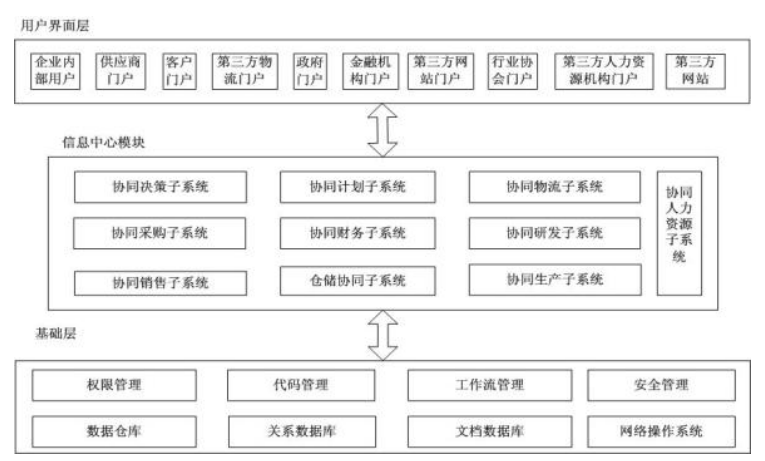

图 2 协同化铜矿企业管理信息系统体系结构图

\section{1 协同决策子系统}

协同决策子系统包括: (1)市场需求预测模块: 铜矿原 矿、粗铜、电解铜、阴极铜、精铜以及其它伴生的矿、废 矿石等等产品的市场需求预测。(2)库存预测模块: 铜矿原 料、产成品、产品、设备、辅助材料的库存量预测。(3)生 产进度模块: 铜矿企业在计划期内应达到的铜矿产品的产 量、品位等生产活动指标进行生产进度的安排。(4)资金预 算模块: (1)铜矿企业主要的产品如精铜以及其它副产品如 硫或铁产品生产量的预计、销售价格预算。(2)总运营费用 预算: 采矿、选矿、治炼成本预算、产品储存成本预算等。 (3)直接材料预算: (4)铜矿矿山的辅助材料、低值易耗品、 备品备件、燃料、产成品等采购成本预算、库存成本预算。 (5)销售费用预算、管理费用预算。6 资本收入预算：投资 项目预计收益、利润预算、未来项目的现金流入量、投资 收益率等。(7)风险预算：铜价格波动风险预算、铜矿运输 风险成本预算、铜矿安全生产风险预算等, 8人力资源培 训、质量管理、安全环保、其他业务预算。(5)采购方案决 策模块，包括：原材料采购决策、设备采购决策等等。

此子系统占据整个系统的首要地位。协同企业外部的 政府、合作企业、供应方、客户，与此子系统信息共享， 才能做出正确、时效的决策, 同时与是对其它子系统协同 工作, 为生产、财务、计划子系统等等起提供决策信息。

\section{2 协同计划子系统}

协同计划子系统是协同铜矿企业各个部门, 根据过去 的生产、销售信息, 协同外部环境信息, 协同决策系统, 为各个部门提供计划信息。协同计划子系统包括：(1) 中
长期(年度)计划模块: 铜矿地质储量消耗计划、新增铜矿地 质储量计划; 铜矿产量计划 (采掘总量、采剥总量); 资源 利用计划 (铜矿矿石损失率、贫化率); 产品产量、销售量、 选矿处理量计划; 各种技术经济指标计划（铜矿品位、回 收率等); 成本费用计划 (物资消耗、备件消耗、设备折旧、 人力成本、费用指标); 盈利计划; 投资及技改项目的进度 计划等。(2) 短期 (月) 计划模块: 铜矿采掘计划; 探矿 计划; 采剥计划; 各采场、各生产单位的出矿量计划其它 工程计划; 物资需求与采购计划; 成本费用计划; 资金计 划安排。

\section{3 协同生产子系统}

协同生产子系统: 是协同铜矿企业计划部门、调度部 门、采矿场、选矿场、冶炼部门、质检部门、安全生产部 门、财务部门等, 协同勘探、采矿、选矿、冶炼等整个生 产过程, 集生产计划模块、生产调度模块、生产数据实时 采集模块、生产数据报表综合管理模块、质检分析模块、 实时保障安全生产模块, 实现根据生产计划执行生产, 生 产数据实时的采集、远程监控生产过程、动态控制生产计 划执行情况、上报以及汇总查询生产统计数据、实时保障 安全生产的系统。

\section{4 协同采购子系统}

协同采购是对整个采购业务流程的协同，包含最初的 需求, 中间的供应商的选择, 以及最后的财务等的协调一 致。形成与计划协同、寻源采购协同、订单协同、物流协 同、财务协同的协同模式。

协同采购子系统包括的各个模块的业务流程的协同过 程: (1)采购计划协同管理模块: 铜矿企业的采购部门根据 企业对原矿石、采掘设备、辅助材料等等的需求, 以及仓 库已有的库存, 得出采购计划。(2)供应商管理模块: 通过 网络, 发布需求信息, 网上公开竞价选择供应商。(3)订单 管理模块：包括合同签订协同管理、合同审批协同管理、 合同执行协同管理等。供应商通过系统查看铜矿企业的采 购部门已审批的采购订单, 确认货物、数量、交货时间等 采购部门对订单合同进度实时跟踪。(4)物流协同管理模块。 (5)仓储协同管理模块。(6)财务协同管理模块：铜矿企业采 购部门在网上签署正式的电子购货合同后, 预付款处理, 货物到货后, 付款结算管理、采购结算管理等, 要与发票 和财务合同协同一致。

\section{5 协同销售子系统}

协同销售子系统包括: (1)产品信息管理模块: 与生产、 仓储子系统协同，铜矿企业的产品信息通过网络发布。(2) 
客户关系管理模块：通过网络营销, 寻找潜在客户客户, 对已有的客户价值判断后进行分级的数据库管理, 实时在 线咨询服务、在线结算付款, 跟踪售后服务等。(3)销售订 单管理模块: 客户通过网络发送订单, 经过铜矿企业的销 售部门审批后的销售订单, 签署电子合同, 销售部门对订 单合同进度实时跟踪。(4)物流协同管理模块。(5)仓储协同 管理模块。(6)财务协同管理模块: 铜矿企业销售部门在网 上签署正式的电子销售合同后, 预收款处理, 货物到货后, 收款结算管理、销售结算管理等。要与发票协同和财务合 同协同。

\section{6 协同物流子系统}

铜矿企业为了科学化管理铜矿企业的生产运输, 将每 种货物按品种统一编号, 每台车辆按车种归类统一编号, 录入协同物流子系统的标准数据库中。物流子系统与生产 子系统、销售子系统协同起来, 共同完成运输任务。

协同物流子系统包括: (1)生产物流模块: 铜矿企业内 部的物流部门利用通勤车辆、特种车辆及生产辅助车辆, 完成铜矿企业的生产原材料、产品铜、硫精矿和及危化品 从采矿场到选矿场、冶炼部门的运输任务。(2)采购、销售 协同物流模块: 有些铜矿企业拥有自有车辆运输产品, 实 时合理地调度自有车辆, 实时监控产品从 (到) 采购商 (客 户）的运输过程。有些铜矿企业选择第三方物流完成产品 从 (到) 采购商 (客户) 的运输过程。铜矿企业通过网络 选择商誉好、价格低的第三方物流, 通过网络与第三方物 流签订运输合同, 通过网络监控第三方物流运输过程, 保 障产品安全、准时地到货。

\section{7 协同财务子系统}

协同财务子系统包括: (1)成本会计模块: 生产成本、 安全成本、环保成本子模块。

(2)财务管理模块：计划预算管理、筹资管理、投资管 理、销售收入利润管理、企业风险管理、盈亏统计管理、 总账管理等。

协同财务子系统是信息系统核心, 企业所有部门有协 作关系的系统。与生产子系统的协同产生生产成本。与决 策子系统协同工作, 为铜矿企业的决策提供决策预算数据。 与人力资源子系统的协同产生人工费数据。另外, 企业所 有外部单位有协作关系的系统。与政府之间的协同产生其 中的矿产资源使用费、土地征用费、资源费。如果有第三 方科研单位或是高校参与研发, 协同产生设计费的数据。 与政府、行业协会协同产生安全成本、环保成本数据。与 对外投资合作企业协同产生筹资管理、投资管理、企业风 险管理成本与费用, 并为铜矿企业对外投资提供决策数据。
4.8 协同仓储管理子系统

协同仓储管理子系统包括: (1)货位与物资数据管理模 块: (1)按照物资类别建立标准编码。将铜矿企业的仓储按 照铜矿企业的原材料、产成品、成品、辅助材料、生产设 备、辅助设备 (例如: 钢材、五金、化工、建材、电材等) 编码。(2)将货位编码定位, 仓库的货位规划, 将货位按照 库房、库区、架、层、位的层次结构进行货位编码。(3)将 物资按照编码, 设置独立区域存储, 严格编码好的每种物 资与规范的货位盘点对位, 建立标准的编码, 准确、科学 的库存货位管理。(2)入库管理模块：记录进货日期、货物 品种及入库数量。包括: 采购订单入库、退货入库、暂存 入库、工程备件、红冲入库等。(3)出库管理模块: 出库管 理分为立即出库或上架入库再出库两种方式。出库管理模 块业务过程: 领取料单、核单、备料、复核、点交、登记 领料库存、期末库存扎帐。与协同物流子系统协同工作, 将货物包装、装配、运送。(4)统计报表模块: 入库物资报 表、出库物资报表、月报、日报仓库出库、入库明细表等。

\section{9 其它子系统}

协同研发子系统是协同政府、第三方科研单位、高校 等机构, 共同开展科研创新工作, 子系统包括: 科研创新 政策环境模块、科研组织管理模块、科研成果应用模块, 科研资金投入模块。

协同人力资源子系统包括招聘配置模块、员工培训模 块、人力资源规划模块、绩效管理模块、薪酬管理模块、 劳动关系模块。该子系统是协同第三方、行业协会, 在网 络上招聘人才。协同行业协会、政府、法律机构建立安全、 健康的劳动关系。协同本企业内部的财务部门建立薪酬管 理, 协同生产部门建立绩效考核管理工作。

\section{参考文献 (References)}

[1] Conn. Stamford, Gartner Group identifies C-Commerce \$supply chain movement: An Emerging trend in Collaborative Web Commu-nities.1999(8).

[2] Philps C, Meeber M. The B2B intemet report Collaborative Commerce. 2000.4

[3] Mahowald cf R, Levitt M. Collaborative applications in B2B eMarketplaces. 2000(7)edge.2000(6).

[4] Giovanna Lo Nigro, Manfredi Bruccoleri, Giovanni Perrone. Nego-tiation in distributed production planning environments. Inter-national Journal of Production Research, 2006, 44(18/19): 3743.

[5] Susna A. sheer, Bill Admas, Collbaoartive Comnreree: The Roleof Intemerdiesine eollbaoration, Jmuoalof Eleertonie Cornrnecre Research, 2001,2(2) :23. 